1 8A constitutive model for the accumulated strain of unsaturated soil under high-cycle traffic loading Zhigang $\mathrm{Cao}^{1}$, Jingyu Chen ${ }^{1}$, Eduardo E. Alonso ${ }^{2}$, Anna Ramon Tarragona ${ }^{2}$, Yuanqiang Cai ${ }^{1,3}$, Chuan $\mathrm{Gu}^{4}$, Qi Zhang ${ }^{1}$

1. Research center of costal and urban Geotechnical Engineering, Zhejiang University, Hangzhou 310058, PR China.

2. Department of Geotechnical Engineering and Geosciences, Universitat Politecnica de Catalunya

\title{
Funding information
}

The National Natural Science Foundation of China (Grant Nos. 51778571, 51978611).

4. College of Civil Engineering and Architecture, The Key Laboratory of Engineering and Technology for Soft Soil Foundation and Tideland Reclamation of Zhejiang Province, Wenzhou University, Wenzhou, PR China

\section{*Correspondence}

Yuanqiang Cai, College of Civil Engineering and Architecture, Zhejiang University, Hangzhou 310058, PR China; College of Civil Engineering and Architecture, Zhejiang Univ. of Technology, Hangzhou 310014, P.R. China.

E-mail: caiyq@zju.edu.cn 


\section{Abstract}

The road base is normally situated above the water table and thus in unsaturated state. Experimental results show that the accumulated strains of the unsaturated road base aggregate under high-cycle traffic loads are significantly influenced by the matric suction. To predict the accumulated strain of unsaturated road base aggregate under high-cycle traffic loads, a constitutive model was developed based on the Barcelona Basic Model (BBM) and the shakedown concept. In this model, the shakedown and plastic creep boundaries of the aggregate under cyclic loads were supposed to exist and to have the same shape as the "static" yield surface in BBM. The strain accumulation rates were described as an exponential function of the distance between the peak cyclic stress point and the conjugated point at the current cyclic yield surface. An explicit calculation methodology was adopted to avoid large calculation errors and to improve the calculation efficiency of the model. Comparison between model predictions and testing results proved the accuracy of the proposed model, which can be used as a basic model to predict the long-term deformation of unsaturated road base aggregate under high-cycle traffic loads.

KEYWORDS strain accumulation, unsaturated soil, high-cycle loads, constitutive model, shakedown 


\section{INTRODUCTION}

The road base and subbase layers are normally situated above the water table and thus in unsaturated state. Heath et al. (2004) ${ }^{19}$ found that the matric suction could reach a significant value of $100 \mathrm{kPa}$ in the road base and subbase layers. During the service lifespan, the road base aggregate may be fouled by fines resulting from factors such as particle breakage, invasion of external fines from surface cracks and subgrade pumping (Huang et al., 2009 ${ }^{21}$; Alonso, $1998^{2}$ ). The inclusion of fines usually intensify the effects of suction on the road base performance. Therefore, it is necessary to investigate the influence of matric suction on the long-term deformation of unsaturated road base under high-cycle traffic loads.

Concerning experimental studies, Ekblad and Isacsson $(2006)^{15}$ improved a triaxial testing system for cyclic loading tests on unsaturated soil by installing a high-capacity suction probe to measure the matric suction during the cyclic loading test. The probe was inserted into the specimen after 20,000 load repetitions to avoid damaging the fragile ceramic tip. The measured matric suction was small (between $13 \mathrm{kPa}$ and $20 \mathrm{kPa}$ ). It was found that coarse materials experienced a small reduction in resilient modulus (within 10\%) when brought close to saturation, while specimens with an increased amount of fines responded with a substantial loss (could reach more than 50\%) of resilient modulus upon saturation.

By applying the axis-translation method, Craciun and Lo (2010) ${ }^{14}$ improved a large-scale triaxial test apparatus with a matric suction controller system. The system enabled the measurement of suction evolution during cyclic loading of an unsaturated road base aggregate. Ishikawa et al. $(2014)^{22}$ upgraded a large-diameter triaxial cell by adopting a high air entry value hydrophilic microporous membrane, instead of the more common ceramic disks, to reduce the equilibrium time in samples. However, they presented limited testing results of the accumulated deformation of the unsaturated aggregate under cyclic loads. Chen et al. (2018) ${ }^{12}$ upgraded a large-scale triaxial apparatus with an unsaturated module and found that the increase of matric suction could lead to a decrease of accumulated deformation and an increase of resilient modulus of road base aggregate at the suction range tested. Gu et al. $(2020)^{17}$ investigated the accumulated strain of an unsaturated aggregate under ascending cyclic stress amplitudes. The plastic shakedown and plastic creep limits of the aggregate were identified based on shakedown theory. These limits were found to increase linearly with the matric suction. 
These experimental results proved the influence of matric suction on the accumulated deformation of road base aggregates. However, few theoretical works are available on the long-term deformation of unsaturated road base aggregates under high-cycle loads based on the framework of unsaturated soil mechanics.

Alonso et al. $(1990)^{3}$ proposed a well-known elasto-plastic model, the Barcelona Basic Model (BBM), to describe the stress-strain behavior of unsaturated soil under monotonic load. This model extended the modified Cam-Clay model (Roscoe and Burland, $1968^{32}$ ) by incorporating a loading collapse yield locus (LC) accounting for the effect of suction on yielding. Later, research contributions were reported to address different materials, hydraulic interactions and computational techniques (e.g. Pereira et al., 2005 ${ }^{31}$; Gens et al., 2006 ${ }^{16}$; Sołowski \& Gallipoli, 2010 ${ }^{34}$; and Bolzon et al., $1996^{6}$ ). These models are applicable to stress-strain relationships under monotonic load.

To capture the strain accumulation of soil under cyclic loading, bounding surface models were developed by many researchers (e.g. Zienkiewicz et al., 1985 ${ }^{39}$; Pastor et al., 1985 ${ }^{28}$; Liang and Ma, $1992^{25}$; and Khalili et al., 2005 ${ }^{24}$ ). The plastic modulus was related to the distance between the current stress point and the conjugated stress point on the bounding surface. Later, Pedroso and Farias $(2011)^{29}$ extended the model to consider the effects of soil saturation on the strain accumulation under cyclic loading by introducing the BBM in a bounding surface framework. Bian and Shahrour (2009) $)^{5}$ developed a cyclic elastoplastic constitutive model within the framework of the theory of Biot/Coussy. The theory accounted for the soil saturation on the response of a sandy soil to both monotonic and cyclic undrained loading paths. All of these models were shown to predict the accumulated deformation for a limited number of loading cycles due to high computational costs and errors in the process of repeated iterative steps, which made them non applicable to high-cycle traffic loads.

Traffic loadings are characterized by a high-cycle (several millions) and small stress amplitude (typically below $200 \mathrm{kPa}$ in the road base). The road base is usually regarded as a purely elastic material under each traffic loading cycle, but non-negligible accumulated strains would be caused when the traffic cycles reach millions during the period of road operation (AASHTO, 2008). To avoid a step-by-step calculation of the entire loading history, Suiker and de Borst $(2003)^{35}$ proposed a constitutive model for ballast materials under high-cycle traffic loadings based on a shakedown concept. The model describes the envelope of permanent deformation generated during the cyclic 
loading process. It was assumed that no permanent deformations would occur if the cyclic load level laid inside an elastic limit, and permanent deformations occurred when the elastic limit was exceeded. Niemunis et al. (2005) ${ }^{27}$ and Wichtmann et al. (2009) ${ }^{38}$ formulated an accumulation model for granular materials (the "Bochum" accumulation model) considering influence factors such as strain amplitude, average stress ratio, void ratio, and the change of the polarization of the strain loop. An explicit calculation method was applied without tracing the oscillating strain path during individual cycles. Karg and Haegeman $(2009)^{23}$ proposed another elasto-plastic long-term model by relating the rate of accumulated deformation to stress state, void ratio, and the cyclic stresses under the assumption of low cyclic stress amplitude with respect to the static part. The models mentioned provided a proper prediction of the long-term deformation of soil under high-cycle traffic loads. However, the effect of matric suction in unsaturated soil was not considered in these high-cycle strain accumulation models. As mentioned above (Chen et al., $2018^{12}$ ), the long-term deformation of unsaturated road base aggregate under high-cycle traffic loads is strongly affected by the matric suction. Therefore, to accurately predict the long-term deformation of road bases under cyclic traffic loads, there is a need to develop a high-cycle strain accumulation model capable of considering the effects of matric suction.

To meet this challenge, the present paper investigates the long-term deformation of unsaturated road base aggregates under high-cycle traffic loads by interpreting a comprehensive set of laboratory tests and developing an elasto-plastic explicit-calculation model, to consider the influence of matric suction in the prediction of the strain accumulation of road base aggregates.

Section 2 reports the results of large-scale cyclic triaxial tests on an unsaturated road base aggregate and the formulation of an extended BBM for strain accumulation under cyclic loading. Section 3 introduces an explicit calculation method. Then, model parameters are calibrated against experimental results in Section 4. In Section 5, a comparison between the predicted and experimental results validates the proposed strain accumulation model.

\section{STRAIN ACCUMULATION AND MODEL FORMULATION}

\subsection{Testing materials and test programs}

The testing materials for the road base and subbase were selected as crushed tuff aggregates. Road base aggregates are often fouled in practice by fines invasion from the top cracks or mud 
pumping from subgrade, which could change significantly the water retention of road base aggregates. To simulate this effect, the crushed tuff aggregates were mixed with Kaolin clay at the dry mass ratio of $3 \%$. This percentage of finess was determined in tests performed in Qianbing road after three years of operation. This road represents typical conditions of a road on soft clay in Eastern China. Fig. 1 shows the gradation curve of the mixture, which is classified as GW group according to the unified soil classification system (ASTM, D2487-17e $1^{4}$ ).

The cyclic loading tests were conducted on the unsaturated road base aggregate in a large-scale tri-axial apparatus considering four different matric suctions $(0 \mathrm{kPa}, 30 \mathrm{kPa}, 60 \mathrm{kPa}$ and $90 \mathrm{kPa})$ and three cyclic deviatoric stress amplitudes $(60 \mathrm{kPa}, 100 \mathrm{kPa}$ and $150 \mathrm{kPa})$ are selected to simulate different traffic weights, such as car, truck and bus. The loading cycle in the experiments is chosen as 50000 as a compromise between the equipment capacity and the cycles needed for the specimen to reach shakedown or collapse state. The details of the experiments can be found in $\mathrm{Gu}$ et al. $2020^{16}$ ). The vertical cyclic loads were applied in a load-controlled fashion by the waveform represented in Fig. 2(a). The loading paths in the $(p, q, s)$ space are shown in Fig. 2(b). The variables $p, q$ and $q^{\mathrm{ampl}}$ are defined as $p=\left(\sigma_{1}+2 \sigma_{3}\right) / 3, q=\sigma_{1}-\sigma_{3}, q^{\mathrm{ampl}}=\triangle \sigma_{1 \mathrm{max}}, p^{\mathrm{ampl}}=\sigma_{3}+q^{\mathrm{ampl}} / 3$, where $\sigma_{1}$ and $\sigma_{3}$ are the excess of principal stresses over pore air pressure in the vertical and radial directions (net stress), respectively, and $\triangle \sigma_{1 \max }$ is the cyclic stress amplitude in the axial direction. The number of loading cycles $N$ was set to 50000, and the loading frequency was $1 \mathrm{~Hz}$.

It is true that the stress paths experienced by road bases during the traffic passage is more complicated than the paths imposed by a triaxial cyclic loading test, even if most of the existing studies used the triaxial loading tests to investigate the cyclic behavior of road base aggregates. In fact, both the normal and shear stress in the road base would vary during the passage of traffic and a principal stress rotation (PSR) would be induced. The hollow cylinder apparatus (HCA) can be used to simulate PSR-induced by moving traffic. Experiments with HCA on clay (Cai et al. 20197) showed that the cyclic loading test, considering PSR, would induce more accumulated strain than the cyclic triaxial loading tests. However, the specimen used in HCA has a geometry ease to accommodate with clays but not so much for unbound granular materials. The main contribution of this study is to investigate the effects of matric suction on the accumulated strain of road base aggregates and to incorporate it in a constitutive model. 


\subsection{Strain accumulation model for unsaturated road base aggregate}

159

160

161

162

It has been widely recognized that the accumulated strain of soil under different cyclic stress amplitudes can be analyzed within the framework of shakedown theory (Sharp and Booker $1984^{33}$, Collins and Boulbibane $2000^{13}$, Werkmeister et al. $2005^{37}$ ). Werkmeister et al. $(2005)^{37}$ proposed that the cyclic response of road base or subbase courses could be classified into three ranges in order of ascending cyclic deviatoric stress levels: plastic shakedown, plastic creep and incremental collapse. When the cyclic stress amplitude is low, the accumulated rate of permanent strain decreases as the loading cycles increase and eventually the accumulation of strains vanishes and the soil is said to be entirely resilient; then the soil reaches a "plastic shakedown" state. As the cyclic stress amplitude increases further, the permanent deformation keeps increasing at a small constant rate; then the soil is said to be in a "plastic creeping" state. If the cyclic stress amplitude exceeds a certain limit, the accumulated rate of permanent strain increases rapidly and the failure occurs within a relatively low number of loading cycles; then it reaches the incremental collapse state. The cyclic stress limits separating the plastic shakedown, plastic creep and incremental collapse ranges are termed as "plastic shakedown limit" and "plastic creep limit", respectively.

Fig. 3 shows the development of plastic axial strain $\left(\varepsilon_{1}^{\mathrm{p}}\right)$ versus the loading cycles $N$ for $q^{\mathrm{ampl}}=60 \mathrm{kPa}, 100 \mathrm{kPa}$, and $150 \mathrm{kPa}$ under different suction magnitudes, $s$. It is shown in Fig. 3(a) for $q^{\mathrm{ampl}}=60 \mathrm{kPa}$, that the plastic axial strains increase rapidly during the initial cyclic loading stage, and then tend to stabilise as the load cycle $N$ increases further, which indicates that the specimen reaches the "shakedown" state. As the magnitude of cyclic load increases, the plastic axial strain increases rapidly and the plastic strain of some specimens will keep increasing with $N$ under certain matric suctions. For $q^{\mathrm{ampl}}=100 \mathrm{kPa}$, the plastic strain of the specimen under $s=0 \mathrm{kPa}$ and $30 \mathrm{kPa}$ increases at given rate when $N$ reaches 50000 cycles ("plastic creep" state) while the plastic strain for $s=60 \mathrm{kPa}$ and $90 \mathrm{kPa}$ becomes nearly stable as $N$ increases ("shakedown" state). For $q^{\text {ampl}}=150$ $\mathrm{kPa}$, the plastic strain of the specimen under $s=0 \mathrm{kPa}, 30 \mathrm{kPa}$ and $60 \mathrm{kPa}$ increases at a non-negligible rate when $N$ reaches 50000 cycles ("plastic creep" state), while the plastic strain for $s=90 \mathrm{kPa}$ becomes nearly stable as $N$ reaches 50000 cycles ("shakedown" state). The details on how to determine the shakedown limits of unsaturated road base aggregate under high-cycle loads can be 
found in Gu et al. $(2020)^{17}$, and it is found that the shakedown limits increase as the suction in the road base aggregated increases.

Based on the experiment results, the unsaturated aggregate would experience shakedown, plastic creep and incremental collapse state under ascending cyclic stress amplitudes, as sketched in Fig. 4(a). Then, the a plastic shakedown limit and a plastic creep limit are assumed to exist in a $p-q$ space which divide the space into three regions: the shakedown region, the plastic creep region and the incremental collapse region, as shown in Fig. 4(b).

In order to facilitate the formulation of the model, the shapes of the plastic shakedown and plastic creep limits will be defined by ellipses, in parallel with the BBM framework. Two average net stresses, $p_{0}{ }^{\text {sh }}$ and $p_{0}{ }^{\mathrm{p}}$, define the position of the shakedown and plastic creep limits on a $(p, q)$ triaxial space, and the superscript "sh" and "p" denotes the shakedown state and plastic creep state, respectively. The average net stress, $p_{0}$, defines the position of the "static" yield surface (Fig. 4b). The limiting boundaries represented in Fig. 4(b) correspond to a given suction $s$. The three limiting curves are assumed to intersect with negative $x$-axis at the same point $\left(-p_{\mathrm{s}}, 0\right), p_{\mathrm{s}}=k s$, where $k$ is a parameter describing the increase in cohesion with suction. The three curves intersect with the positive $x$-axis at $\left(p_{0}^{\text {sh }}, 0\right),\left(p_{0}^{\mathrm{p}}, 0\right),\left(p_{0}, 0\right)$, respectively.

The accumulation of plastic cyclic strains will be determined by defining a "cyclic yield locus" which evolves from an initial cyclic yield locus, limiting an elastic region, towards the plastic shakedown limit. The hardening of this cyclic yield locus depends on the accumulated volumetric plastic strains. The plastic shakedown case is considered in Fig. 5(a). The applied cyclic stress peak $\left(p^{\mathrm{ampl}}, q^{\mathrm{ampl}}\right)$ remains within the plastic shakedown domain. The cyclic yield surface passing through $\left(p^{\mathrm{ampl}}, q^{\mathrm{ampl}}\right)$ defines the final position of the cyclic yield surface. This final position is defined by an isotropic net yield stress, $p_{0}^{\mathrm{e}(F)}$. The current cyclic yield surface for a given number of applied loading cycles spans the stress region between the initial cyclic yield surface and the final one, as plastic volumetric strains accumulate. The size of the current cyclic yield surface is determined by the isotropic net yield stress $p_{0}^{\mathrm{e}(C)}$.

An initial cyclic yield stress, $p_{0}^{\mathrm{e}(\mathrm{I})}$, defines the elastic region. The value of $p_{0}^{\mathrm{e}(\mathrm{I})}$ depends on the soil density and suction. When the peak cyclic stress point $\left(p^{\mathrm{ampl}}, q^{\mathrm{ampl}}\right)$ is located inside the initial cyclic yield surface, only elastic deformations occur, and the initial cyclic yield surface and 
the static yield surface remain stationary. In the present study, $p_{0}^{\mathrm{e}(\mathrm{I})}$ is chosen as the initial net confining pressure $\sigma_{3}$ of triaxial tests performed, for simplicity. When the peak cyclic stress point $\left(p^{\mathrm{ampl}}, q^{\mathrm{ampl}}\right)$ is outside the initial cyclic yield surface as shown in Fig. 5(a), plastic deformations develop. The initial cyclic yield surface expands to the current cyclic yield surface due to compaction effect of the cyclic loadings, until it reaches the final cyclic yield surface $\left(p_{0}^{\mathrm{e}(\mathrm{F})}\right)$.

When the current cyclic yield surface coincides with the final cyclic yield surface, the model formulation should make sure that no further plastic deformations occur, i.e. the accumulated volumetric plastic strain rate becomes zero. This corresponds to a plastic shakedown behavior. It is expected that the increase in density induced by the cyclic loading will expand the shakedown, plastic creep and static yield domains, which is indicated in Fig. 5(a).

Consider now, in Fig. 5(b), the case leading to a progressive accumulation of plastic strains during cyclic loading. The peak cyclic stress point $\left(p^{\mathrm{ampl}}, q^{\mathrm{ampl}}\right)$ is now located in the plastic creep domain (region II). In this case, it will be accepted that the final cyclic yield surface will not exceed the position of the shakedown surface. However, the model will predict that the loading cycles lead to a (small) constant accumulation of plastic volumetric strains. Again, the accumulation of plastic strains will expand the three limit states defined.

The experimental results on road base aggregates under cyclic loads at shakedown and plastic creep ranges indicated that the permanent deformation increased with the increase of load cycles at a declining rate (Cao et al. 2017 $7^{9}$; Chen et al. $2018^{12}$; Gu et al. $2020^{17}$ ). Thus, it is assumed that the rate of accumulated strain depends on the distance between the peak cyclic stress $\left(p^{\mathrm{ampl}}, q^{\mathrm{ampl}}\right)$ and the stress point $(\hat{p}, \hat{q})$ located on the current cyclic yield surface. $(\hat{p}, \hat{q})$ is the intersection point between the loading path and the current cyclic yield surface, as shown in Fig. 5.

The expressions $\frac{p^{\text {ampl }}-\hat{p}}{p^{\text {ampl }}-\sigma_{3}}$ and $\frac{q^{\text {ampl }}-\hat{q}}{q^{\text {ampl }}}$ define, in a normalized manner, the distance between the peak mean and deviatoric cyclic stresses and their image on the current cyclic yield locus. The rates of accumulated plastic volumetric and deviatoric strains $\left(\varepsilon_{\mathrm{v}}^{\mathrm{p}}, \varepsilon_{\mathrm{q}}^{\mathrm{p}}\right)$ are defined by the following equations:

$$
\frac{d \varepsilon_{\mathrm{v}}^{\mathrm{p}}}{d N}=B\left(\frac{p^{\mathrm{ampl}}-\hat{p}}{p^{\mathrm{ampl}}-\sigma_{3}}\right)^{C}
$$




$$
\frac{d \varepsilon_{\mathrm{q}}^{\mathrm{p}}}{d N}=D\left(\frac{q^{\mathrm{ampl}}-\hat{q}}{q^{\mathrm{ampl}}}\right)^{E}
$$

$243 \quad$ where, $\varepsilon_{\mathrm{v}}^{\mathrm{p}}=\varepsilon_{1}^{\mathrm{p}}+\varepsilon_{2}^{\mathrm{p}}+\varepsilon_{3}^{\mathrm{p}}, \quad \varepsilon_{\mathrm{q}}^{\mathrm{p}}=2\left(\varepsilon_{1}^{\mathrm{p}}-\varepsilon_{3}^{\mathrm{p}}\right) / 3, \quad \varepsilon_{1}^{\mathrm{p}}$ and $\varepsilon_{3}^{\mathrm{p}}$ represent the plastic principal strains in 244 the vertical and radial direction, respectively. $B, C, D, E$ are model parameters to be determined.

In selecting this structure for equations (1) and (2) it was recognized that the rate of change of 246 plastic strains with the number of cycles should be a small quantity. Since it is suggested that it will be proportional to a stress ratio taking values in the range 0 to 1 (equations (1) and (2)) it was thought that a power function in terms of exponents $\mathrm{C}>1$ and $\mathrm{D}>1$ would be convenient. In fact, the powers $\mathrm{C}=8.2$ and $\mathrm{D}=8.6$ indicate the slow rate of plastic strain accumulation. Probably, in view of the numerical values determined (8.2 and 8.6) a unique power coefficient could be sufficiently accurate to predict the accumulation of volumetric and deviatoric strains. Coefficients B and $\mathrm{D}$ add some flexibility to the model.

The current cyclic yield surface containing the intersection point $(\hat{p}, \hat{q})$ can be expressed as:

$$
\hat{q}^{2}-M^{2}(\hat{p}+k s)\left(p_{0}^{\mathrm{e}(\mathrm{C})}-\hat{p}\right)=0
$$

where $M$ represents the slope of critical state line. As the point $(\hat{p}, \hat{q})$ is in the drained tri-axial loading path, the following equation can be obtained:

$$
\hat{q}=3\left(\hat{p}-\sigma_{3}\right)
$$

Equation (3) and Equation (4) provide the point $(\hat{p}, \hat{q})$ :

$$
\begin{gathered}
\hat{p}=\frac{18 \sigma_{3}+M^{2}\left(p_{0}^{\mathrm{e}(\mathrm{C})}-k s\right)+\sqrt{M^{4}\left(p_{0}^{\mathrm{e}(\mathrm{C})}+k s\right)^{2}+36 M^{2}\left(\sigma_{3}+k s\right)\left(p_{0}^{\mathrm{e}(\mathrm{C})}-\sigma_{3}\right)}}{18+2 M^{2}} \\
\hat{q}=\frac{54 \sigma_{3}+3 M^{2}\left(p_{0}^{\mathrm{e}(\mathrm{C})}-k s\right)+3 \sqrt{M^{4}\left(p_{0}^{\mathrm{e}(\mathrm{C})}+k s\right)^{2}+36 M^{2}\left(\sigma_{3}+k s\right)\left(p_{0}^{\mathrm{e}(\mathrm{C})}-\sigma_{3}\right)}}{18+2 M^{2}}-3 \sigma_{3}
\end{gathered}
$$

The volumetric hardening law in BBM for the current cyclic yield surface can be expressed as:

$$
\frac{d p_{0}^{\mathrm{e}(\mathrm{C}) *}}{p_{0}^{\mathrm{e}(\mathrm{C}) *}}=\omega_{1} \frac{v}{\lambda(0)-\kappa} d \varepsilon_{\mathrm{v}}^{\mathrm{p}}
$$

where the superscript $\left(^{*}\right)$ refers to the saturated state, $\omega_{1}$ is a hardening law parameter and $p_{0}^{\mathrm{e}(\mathrm{C}) *}$ 264 is the saturated isotropic yield stress for the current cyclic yield surface. Other parameters can be found in the Notation list, which includes the parameters for BBM. The interpretation of BBM 
parameters is given in the original reference (Alonso et al. 1990 ${ }^{3}$ ).

The loading collapse yield curve of BBM, in the $p-s$ plane, allows the calculation of the isotropic yield stress $p_{0}^{\mathrm{e}(C)}$ for a given suction $s$ :

$$
p_{0}^{\mathrm{e}(\mathrm{C})}=p_{\mathrm{c}}\left(\frac{p_{0}^{\mathrm{e}(\mathrm{C}) *}}{p_{\mathrm{c}}}\right)^{\frac{\lambda(0)-\kappa}{\lambda(s)-\kappa}}
$$

where, $p_{\mathrm{c}}$ is a reference stress, $\lambda(s)$ is the stiffness parameter for changes in suction for virgin states of the soil.

Integrating both sides of the hardening law in Equation 7, the isotropic yield stress for the current cyclic yielding surface $p_{0}^{\mathrm{e}(\mathrm{C}) *}$ can be obtained as:

$$
p_{0}^{\mathrm{e}(\mathrm{C}) *}=\exp \left(\omega_{1} \frac{v}{\lambda(0)-\kappa} \varepsilon_{\mathrm{v}}^{\mathrm{p}}+A\right)
$$

where, $A$ is a model parameter related to the preconsolidation pressure of initial cyclic yielding locus at saturated state.

Substituting Equation (9) into Equation (8), the pre-consolidation pressure $p_{0}^{\mathrm{e}(\mathrm{C})}$ can be expressed as:

$$
p_{0}^{\mathrm{e}(\mathrm{C})}=p_{c}\left(\frac{\exp \left(\omega_{1} \frac{v}{\lambda(0)-\kappa} \varepsilon_{\mathrm{v}}^{\mathrm{p}}+A\right)}{p_{c}}\right)^{\frac{\lambda(0)-\kappa}{\lambda(s)-\kappa}}
$$

The specific volume $v$ in Equation (9) can be further expressed as:

$$
v=\left(1+e_{0}\right)\left(1-\varepsilon_{\mathrm{v}}^{\mathrm{p}}\right)
$$

where, $e_{0}$ is the initial void ratio.

Taking equations (10) and (11) into equations (5) and (6), the equations for the intersection point $(\hat{p}, \hat{q})$ can be updated and $p_{0}^{\mathrm{e}(\mathrm{C})}$ is eliminated. Then through equations (1) and (2), the volumetric and deviatoric strain rates at different loading cycles can be obtained.

When the peak cyclic stress point $\left(p^{\text {ampl }}, q^{\text {ampl}}\right)$ is located in the plastic shakedown domain, the stress point $(\hat{p}, \hat{q})$ will eventually reach the peak stress point $\left(p^{\mathrm{ampl}}, q^{\mathrm{ampl}}\right)$, which implies that $p_{0}^{\mathrm{e}(\mathrm{C})}=p_{0}^{\mathrm{e}(\mathrm{F})}$ and the rate of accumulation of plastic strains (equation (1) and (2)) will vanish.

Note that, since the peak cyclic stress point $\left(p^{\mathrm{ampl}}, q^{\mathrm{ampl}}\right)$ is on the final cyclic yield surface, the 
following equations holds:

$$
q^{\mathrm{ampl} 2}-M^{2}\left(p^{\mathrm{ampl}}+k s\right)\left(p_{0}^{\mathrm{e}(\mathrm{F})}-p^{\mathrm{ampl}}\right)=0
$$

and the final isotropic net field stress is given by:

$$
p_{0}^{\mathrm{e}(\mathrm{F})}=\frac{k s M^{2} p^{\mathrm{ampl}}+M^{2} p^{\mathrm{ampl2}}+q^{\mathrm{ampl} 2}}{M^{2}\left(k s+p^{\mathrm{ampl}}\right)}
$$

For a cyclic stress point $\left(p^{\text {ampl }}, q^{\text {ampl }}\right)$ located in the plastic creep domain, the stress point $(\hat{p}, \hat{q})$ at the final cyclic yield surface should not reach the point $\left(p^{\text {ampl }}, q^{\text {ampl }}\right)$ to avoid the cancellation of plastic strains. Rather, it will be accepted that $(\hat{p}, \hat{q})$ remains at the plastic shakedown limit for any subsequent plastic straining.

The laboratory results, summarized in Fig. 3, indicate that the tested soils exhibited a stable rate of plastic accumulated strains for the cases in the plastic creep range. This stable rates, which may be determined by the tests for the high range of applied cycles (say, for $N>5000$ cycles), will be denoted by $\dot{\varepsilon}_{\mathrm{v} \text {-sta }}^{\mathrm{p}}$ and $\dot{\varepsilon}_{\mathrm{q} \text {-sta }}^{\mathrm{p}}$. These two stationary strain rates allow the determination of the position of the plastic shakedown limit. In fact, in view of equations (1) and (2), the current stress state for a stable plastic strain rate is given by:

$$
\begin{gathered}
\hat{p}=p^{\mathrm{ampl}}-\left(p^{\mathrm{ampl}}+p_{\mathrm{s}}\right)\left(\frac{\dot{\varepsilon}_{\mathrm{v}-\mathrm{sta}}^{\mathrm{p}}}{B}\right)^{1 / C} \\
\hat{q}=q^{\mathrm{ampl}}\left[1-\left(\frac{\dot{\varepsilon}_{\mathrm{q}-\mathrm{sta}}^{\mathrm{p}}}{D}\right)^{1 / E}\right]
\end{gathered}
$$

Then, the shakedown isotropic stress $\left(p_{0}^{\text {sh }}\right)$ is given by substituting $\hat{p}$ and $\hat{q}$ by Equation (14) and Equation (15) for $p^{\text {ampl }}$ and $q^{\text {ampl }}$ in Equation (13), respectively. These relationships complete the formulation of the model.

The traffic-induced cyclic stresses in road bases are relatively small and thus the incremental collapse domain III is not considered in this paper.

\section{EXPLICIT CALCULATION STRATEGY}

Two different calculation strategies, implicit and explicit, are normally used to calculate the long-term deformation of materials under large number of cyclic loadings. Equation (16) describes the state of a system for a new cycle $(N+1)$. 
In Equation (16), $\Gamma(N)$ is the state of current cycle, $N$. This method was usually adopted in the elasto-plastic multi-surface models (Mroz et al., $1978^{26}$; Chaboche, $1994^{11}$ ) and hypoplastic models (Von Wolffersdorff, $1996^{36}$ ). The implicit method requires large computational times, which may result in high computation errors due to a large number of iterative steps, thus it is suitable for small number of loading cycles.

The explicit method is more suitable to calculate the long-term deformation of materials under a large number of cyclic loadings (Suiker and de Borst 2003 35 ; Wichtmann et al. 2009 ${ }^{38}$; Karg and Haegeman $2009^{23}$ ). Fig. 6 shows the schematic diagram for the explicit method. In the explicit methodology, only a few representative cycles are selected to be calculated implicitly. The cycles between two implicit cycles are regarded as explicit parts. The state change during explicit parts are written as:

$$
\Gamma(N+\Delta N)=\Gamma(N)+\Delta N \cdot \Delta \Gamma(N)
$$

where $\Delta N$ is a given increment of loading cycles. $\Delta \Gamma(N)$ is the state increment calculated at the $N$ th cycle.

In the present study, the explicit method was adopted. The rate of accumulated volumetric strain $\frac{d \varepsilon_{\mathrm{v}}^{\mathrm{p}}}{d N}$ and deviatoric strain $\frac{d \varepsilon_{\mathrm{q}}^{\mathrm{p}}}{d N}$ for the $N$ th implicit cycle can be calculated through Eqation (1) and Equation (2). Then the final volumetric and deviatoric strain can be obtained through:

$$
\begin{aligned}
& \varepsilon_{\mathrm{v}}^{\mathrm{p}}(N+\Delta N)=\varepsilon_{\mathrm{v}}^{\mathrm{p}}(N)+\Delta N\left(\frac{d \varepsilon_{\mathrm{v}}^{\mathrm{p}}}{d N}\right) \\
& \varepsilon_{\mathrm{q}}^{\mathrm{p}}(N+\Delta N)=\varepsilon_{\mathrm{q}}^{\mathrm{p}}(N)+\Delta N\left(\frac{d \varepsilon_{\mathrm{q}}^{\mathrm{p}}}{d N}\right)
\end{aligned}
$$

The first few cycles are usually not stable due to experimental difficulties. In the present study, the 10th cycle becomes stable, which is selected to be the first implicit cycle in the calculation. In the calculations presented below $\Delta N$ represents 1000 loading cycles.

\section{MODEL CALIBRATION}

Alonso et al $(1990)^{3}$ describe the procedure to derive the BBM model parameters when suction 
controlled tests are available. The parameters $\lambda(0), \kappa, p_{\mathrm{c}}, r$ and $\beta$ in the present study are obtained through the isotropic drained compression test (loading and unloading) in a triaxial apparatus at the suction values of $0 \mathrm{kPa}$ and $30 \mathrm{kPa}$. The parameters $k$ and $M$ are obtained through monotonic shear tests at different suctions. Figure 7 shows the results of the isotropic and triaxial tests performed to determine the BBM parameters, which are collected in Table 1.

In order to calibrate the parameters in the strain accumulation model, Fig. 8 presents the volumetric and deviatoric plastic strain rates (average rate of every 1000 cycles) versus the accumulated plastic volumetric strains derived from the testing results under $q^{\mathrm{ampl}}=100 \mathrm{kPa}$, a confining stress of $40 \mathrm{kPa}$ and four different suctions. Through the measured results in Fig. 8 , the model parameters $(A, B, C, D, E)$ can be calibrated by fitting the results (see Table 2).

The zero-suction experiments for the deviatoric strains are not correctly fitted. There may be two reasons for this discrepancy. The first reason is that the testing procedure for the saturated case is quite different from the unsaturated one. Samples were saturated by means of a high back pressure, by injecting $\mathrm{CO}_{2}$ into the water for 6 hours, then increasing the back pressure until the Skempton's pore pressure parameter B $>0.95$ was achieved. The suction in unsaturated samples was induced by an axis-translation technique, and it takes time to reach the soil-water equilibrium before the cyclic loading test can be started. It is believed that the different testing procedure would bring some difference in the results. The second reason concerns the calibration procedure, since the model is mainly calibrated by the four tests on unsaturated samples.

Fig. 9 presents, for the set of parameters given in Tables 1 and 2, the predicted and measured volumetric and deviatoric strains under $q^{\mathrm{ampl}}=100 \mathrm{kPa}$ versus the number of loading cycles, $N$. The predicted and measured strains agree reasonably well for the range of applied suctions ( 0 to $90 \mathrm{kPa}$, a range of suctions typically found in road bases).

\section{MODEL VALIDATION}

Two large-scale cyclic triaxial were conducted under two different suctions, $s=45 \mathrm{kPa}$ and 75 $\mathrm{kPa}\left(\sigma_{3}=40 \mathrm{kPa}\right.$ and $\left.q^{\mathrm{ampl}}=100 \mathrm{kPa}\right)$ to validate the applicability of the proposed model under different matric suctions. Fig. 10 shows a comparison between testing and predicted results with the same model parameters. It is shown that the predicted and measured results agree well. 
In addition, to verify the applicability of the proposed model under different cyclic stress amplitudes, the calculated accumulated strains under stresses well below $\left(q^{\text {ampl }}=60 \mathrm{kPa}\right)$ and above $\left(q^{\text {ampl }}=150 \mathrm{kPa}\right)$ the calibrating deviatoric stress $\left(q^{\mathrm{ampl}}=100 \mathrm{kPa}\right)$ are compared with experimental results.

For $q^{\text {ampl }}=60 \mathrm{kPa}$, as shown in Fig. 11 and Fig.12, the strain rate and the accumulated strain with load cycles can be predicted reasonably well by the proposed model. For the case of $q^{\mathrm{ampl}}=150 \mathrm{kPa}$ as shown in Fig. 13 and Fig. 14, the proposed model can also predict satisfactorily the strain rate and strain accumulation with the number of cycles.

\section{CONCLUSIONS}

Based on the experimental results of the accumulated strain of unsaturated road base aggregate under high-cycle loads, a strain accumulation model was proposed to calculate the accumulated strain of unsaturated road base aggregate under cyclic loads. The model combines two reference theories: the elasto-plastic framework of the BBM model and the shakedown concept.

The accumulated strain rate was described as an exponential function of the distance between the cyclic peak stress point and the image point at the current cyclic yield surface. Then, an explicit-calculation method was adopted to improve the calculation precision and efficiency when dealing with high-cycle traffic loadings.

The results of a series of long term cyclic triaxial tests performed (50000 cycles) at four suction levels $(0,30,60$ and $90 \mathrm{kPa})$ and at a common confining and cyclic stress, allowed the estimation of model paramenters.

The capability of the model was checked against long term cyclic triaxial tests performed at other suction levels and different cyclic stress amplitudes. The agreement between model and testing results was quite satisfactory. This exercise provided a validation for the model. The comparison was made in terms of measured and computed volumetric and deviatoric strains. It is concluded that the explicit calculation procedure and the theoretical basic model can predict the long-term deformation of unsaturated road base aggregate reasonably well in the range of matric suctions and cyclic loadings considered. The model is strictly valid for triaxial conditions. However it can be generalized without difficulties to a three-dimensional stress state. Then, it can be applied to analyze the accumulation of strains of road bases under the application of high-cycle traffic load 
conditions The model can-serve as a basic tool to-calculate the accumulated-strain-of unsaturated road base aggregates under high-cycle traffic loads.

399

400

401

402

403

404

\section{ACKNOWLEDGEMENTS}

The authors wish to acknowledge the support of the National Natural Science Foundation of China (Grant Nos. 51778571, 51978611).

\section{CONFLICT OF INTEREST}

There are no competing interests in this paper. 


\section{REFERENCES}

1. AASHTO. (2008). Mechanistic-empirical pavement design guide, interim edition: A manual of practice, American Association of State Highway and Transportation Officials (AASHTO), Washington, DC.

2. Alonso, E. E., (1998). Suction and moisture regimes in roadway bases and subgrades. Proceedings of the International Symposium on Internal Drainage of Road Bases and Subgrade, Granada, 57-104

3. Alonso, E. E., Gens, A., \& Josa, A. (1990). A constitutive model for partially saturated soils. Géotechnique, 40(3), 405-430.

4. ASTM International. (2017). D2487-17e1 Standard Practice for Classification of Soils for Engineering Purposes (Unified Soil Classification System).

5. Bian, H. \& Shahrour, I. (2009). Numerical model for unsaturated sandy soils under cyclic loading: Application to liquefaction. Soil Dyna. Earthquake Engng. 29, №. 2, 237-244.

6. Bolzon, G., Schrefler, B. A. \& Zienkiewicz, O. C. (1996). Elastoplastic soil constitutive laws generalized to partially saturated states. Géotechnique, 46, No. 2, 279-289.

7. Cai, Y.Q., Guo, L., Jardine, R. L., Yang, Z.X. \& Wang, J. (2017). Stress-strain response of soft clay to traffic loading, Geotechnique, 67, No. 5, 446-451.

8. Cai, Y., Chen, J., Cao, Z., Gu, C. \& Wang, J. (2017). Influence of Grain Gradation on Permanent Strain of Unbound Granular Materials under Low Confining Pressure and High-Cycle Loading. Int. J. Geomech. 18, No. 3, 04017156-1-11.

9. Cao, Z., Chen, J., Cai, Y., Gu, C. \& Wang, J. (2017). Effects of moisture content on the cyclic behavior of crushed tuff aggregates by large-scale tri-axialtriaxial test. Soil Dyna. Earthquake Engng. 95, 1-8.

10. Cerni, G., Cardone, F. \& Virgili, A. (2012). Characterisation of permanent deformation behaviour of unbound granular materials under repeated triaxial loading. Construction and Building Materials, 28, No. 1, 79-87.

11. Chaboche, J. L. (1994). Modeling of ratchetting: evaluation of various approaches. European J. Mech. A. Solids, 13, No. 4, 501-518.

12. Chen, J, Alonso, E. E. \& Gu C., et al. (2018). Long term cyclic behavior of unsaturated granular soils[J]. Transportation Geotechnics, 17, 48-55.

13. Collins, I.F. \& Boulbibane M. (2000). Geomechanical Analysis of Unbound Pavements Based on Shakedown Theory. J. Geotech. Geoenviron. Eng., 126, No. 1, 50-59. 
14. Craciun, O. \& Lo, S. C. R. (2010). Matric suction measurement in stress path cyclic triaxial testing of unbound granular base materials. Geotechnical Testing Journal, 33, No.1, 33-44.

15. Ekblad, J. \& Isacsson, U. (2006). Influence of water on resilient properties of coarse granular materials. Road materials and pavement design, 7, No.3, 369-404.

16. Gens, A., Sánchez, M. \& Sheng, D. (2006). On constitutive modelling of unsaturated soils. Acta Geotechnica 1, No. 3, 137-147.

17. Gu, C., Zhan, Y., Wang, J., Cai, Y., Cao, Z., and Zhang, Q. (2020). Resilient and permanent deformation of unsaturated unbound granular materials under cyclic loading by the large-scale triaxial tests, Acta Geotech., DOI: 10.1007/s11440-020-00966-0.

18. Guo, L., Cai, Y., Jardine, R., Yang, Z., and Wang, J. (2018). Undrained behavior of intact soft clay under cyclic paths that match vehicle loading conditions. Can. Geotech. J. 55, 90-106.

19. Heath, A. C., Pestana J. M., Harvey, J. T. \& Bejerano, M. O. (2004). Normalizing behaviour of unsaturated granular pavement materials. J. Geotech. Geoenviron. Eng., 130, No.9, 896 - 904.

20. Hilf, J. W. (1956). An investigation of pore-water pressure in compacted cohesive soils. Technical Memorandum No. 654, PhD thesis, Design and Construction Division, Bureau of Reclamation, United States Department of the Interior, Denver.

21. Huang, H., Tutumluer, E., \& Dombrow, W. (2009). Laboratory characterization of fouled railroad ballast behavior. Journal of Transportation Research Board, 93-101.

22. Ishikawa, T., Zhang, Y., Tokoro, T. \& Miura, S. (2014). Medium-size triaxial apparatus for unsaturated granular subbase course materials. Soils and Foundations, 54, No.1, 67-80.

23. Karg, C., \& Haegeman, W. (2009). Elasto-plastic long-term behavior of granular soils: Experimental investigation. Soil dynamics and earthquake engineering, 29(1), 155-172.

24. Khalili, N., Habte, M. A. \& Valliappan, S. (2005). A bounding surface plasticity model for cyclic loading of granular soils. Int. J. Numer. Meth. Engng. 63, No.14, 1939-1960.

25. Liang, R. Y. \& Ma, F. (1992). Anisotropic plasticity model for undrained cyclic behavior of clays. I: Theory. J. Geotech. Engng. 118, No.2, 229-245.

26. Mroz, Z., Norris, V. A. \& Zienkiewicz, O. C. (1978). An anisotropic hardening model for soils and its application to cyclic loading. Int. J. Numer. Analyt. Meth. Geomech. 2, No. 3, 203-221.

27. Niemunis, A., Wichtmann, T. \& Triantafyllidis, T. (2005). A high-cycle accumulation model for sand. Comput. Geotech., 32, No. 4, 245-263.

28. Pastor, M., Zienkiewicz, O. C. \& Leung, K. H. (1985). Simple model for transient soil loading in earthquake analysis. II. Non-associative models for sands. Int. J. Numer. Analyt. Meth. Geomech. 9, No. 5, 477-498. 
29. Pedroso, D. M. \& Farias, M. M. (2011). Extended Barcelona basic model for unsaturated soils under cyclic loadings. Comput. Geotech. 38, No. 5, 731-740.

30. Pereira, E. E., Gens, A. \& Josa, A. (1990). A constitutive model for partially saturated soils. Géotechnique, 40, No. 3, 405-430.

31. Pereira, J. M., Wong, H. \& Dubujet, P., et al. (2005). Adaptation of existing behaviour models to unsaturated states: Application to CJS model. Int. J. Numer. Analyt. Meth. Geomech. 29, No. 11, 1127-1155.

32. Roscoe, K. H. \& Burland, J. B. (1968). On the generalized stress-strain behaviour of wet clay. J. Heyman, F.A. Leckie (Eds.), Engineering plasticity, Cambridge University Press, 535-609.

33. Sharp, R.W. \& Booker J.R. (1984). Shakedown of pavements under moving surface loads. J. Transp. Eng. 110, No.1, 1-14.

34. Sołowski, W.T. \& Gallipoli, D. (2010). Explicit stress integration with error control for the Barcelona Basic Model. Part I: Algorithms formulations. Comput. Geotech. 37, No. (1-2), 59-67.

35. Suiker, A. S. J. \& de Borst, R. (2003). A numerical model for the cyclic deterioration of railway tracks. Int. J. Numer. Meth. Engng. 57, (4), 441-470.

36. Von Wolffersdorff, P. A. (1996). A hypoplastic relation for granular materials with a predefined limit state surface. Mechanics of Cohesive-frictional Materials: Modelling and Computation of Materials and Structures, 1, No. 3, 251-271.

37. Werkmeister, S., Dawson, A.R. \& Wellner, F. (2005). Permanent deformation behavior of granular materials. Road materials and pavement design 6, No. 1, 31-51.

38. Wichtmann, T., Rondón, H. A. \& Niemunis, A. (2009). Prediction of permanent deformations in pavements using a high-cycle accumulation model. J. Geotech. Geoenviron. Engng. 136, No. 5, 728-740.

39. Zienkiewicz, O. C., Leung, K. H. \& Pastor, M. (1985). Simple model for transient soil loading in earthquake analysis. I. Basic model and its application. Int. J. Numer. Analyt. Meth. Geomech. 9, No. 5, 453-476. 
$498 \quad$ List of captions

499 Table captions

500 TABLE 1 Basic model parameters for BBM

501 TABLE 2 Parameters for the strain accumulation model

502 
504 FIGURE 1 Gradation curves of tuff aggregates and kaolin clay

505 FIGURE 2 Applied cyclic stress

506 FIGURE 3 Cyclic triaxial tests on unsaturated crushed tuff aggregates. Accumulated axial strain 507 versus $N$ under different suction

508 FIGURE 4 Three categories of cyclic behaviors within shakedown theory. a) Accumulation of 509 plastic strain in terms of $N$. b) Deformation regions in triaxial stress space for a given suction 510 FIGURE 5 Extended BBM for cyclic loading 511 FIGURE 6 Schematic diagram of explicit method

512 FIGURE 7 Test results for BBM parameter calibration

513 FIGURE 8 Accumulated strain rate versus accumulated volumetric strain, $q^{\text {ampl }}=100 \mathrm{kPa}$.

514 FIGURE 9 Comparison between predicted and tested accumulated strain for $q=100 \mathrm{kPa}$.

515 FIGURE 10 Model validation for $s=45 \mathrm{kPa}$ and $75 \mathrm{kPa}$

516 FIGURE 11 Accumulated strain rate versus accumulated volumetric strain, $q^{\text {ampl }}=60 \mathrm{kPa}$.

517 FIGURE 12 Accumulated volumetric and deviatoric strains with the number of cycles, $q=60 \mathrm{kPa}$

518 FIGURE 13 Accumulated strain rate versus accumulated volumetric strain, $q^{\text {ampl }}=150 \mathrm{kPa}$.

519 FIGURE 14 Accumulated volumetric and deviatoric strains with the number of cycles, $q=150 \mathrm{kPa}$ 
TABLE 1 Basic model parameters for BBM

\begin{tabular}{lccccccc}
\hline$\lambda(\mathbf{0})$ & $\boldsymbol{\kappa}$ & $\boldsymbol{p}_{\mathbf{c}}(\mathbf{k P a})$ & $\boldsymbol{e}_{\mathbf{0}}$ & $\boldsymbol{k}$ & $\boldsymbol{r}$ & $\beta\left(\mathbf{M P a}^{-\mathbf{1}}\right)$ & $\boldsymbol{M}$ \\
\hline 0.01 & 0.002 & 40 & 0.345 & 0.65 & 0.8 & 12.5 & 1.72 \\
\hline
\end{tabular}

521

TABLE 2 Parameters for the strain accumulation model

\begin{tabular}{lllllll}
\hline $\boldsymbol{A}$ & $\boldsymbol{B}$ & $\boldsymbol{C}$ & $\boldsymbol{D}$ & $\boldsymbol{E}$ & $\boldsymbol{\omega}_{\mathbf{1}}$ & $\boldsymbol{p}_{\mathbf{0}}^{\mathrm{e}(\mathrm{I})}$ \\
\hline 5.6 & 1 & 8.2 & 0.34 & 8.6 & 3.5 & $40.0 \mathrm{kPa}$ \\
\hline
\end{tabular}




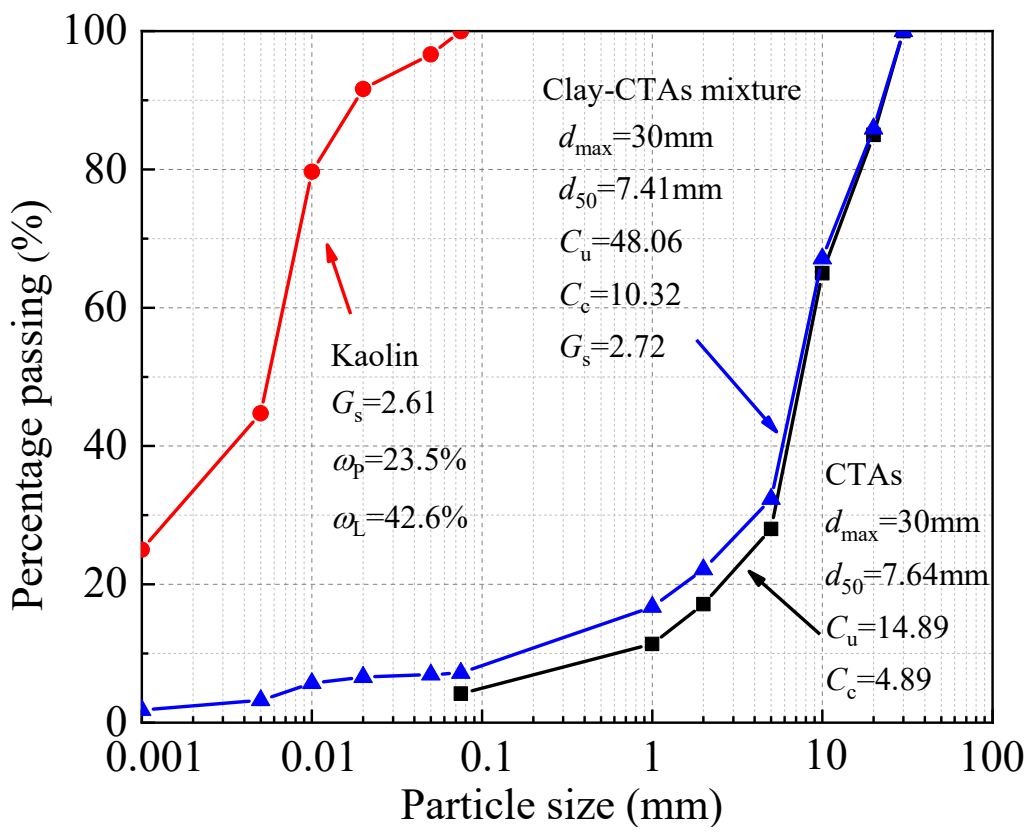

525

FIGURE 1 Gradation curves of tuff aggregates and kaolin clay

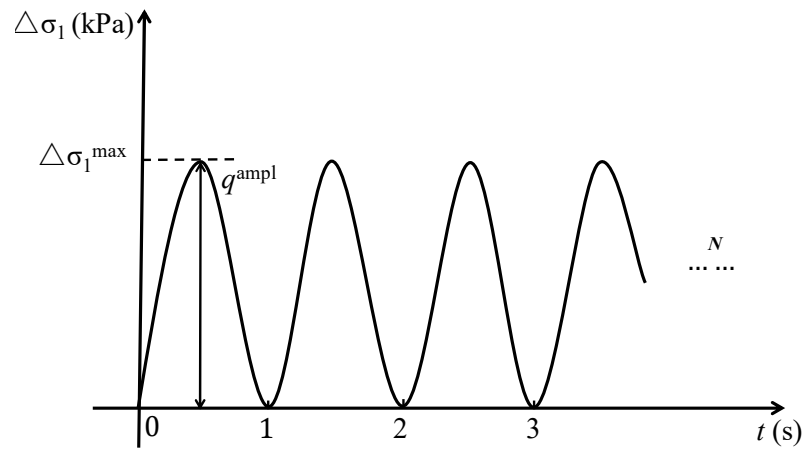

(a) Wave form of the cyclic stress

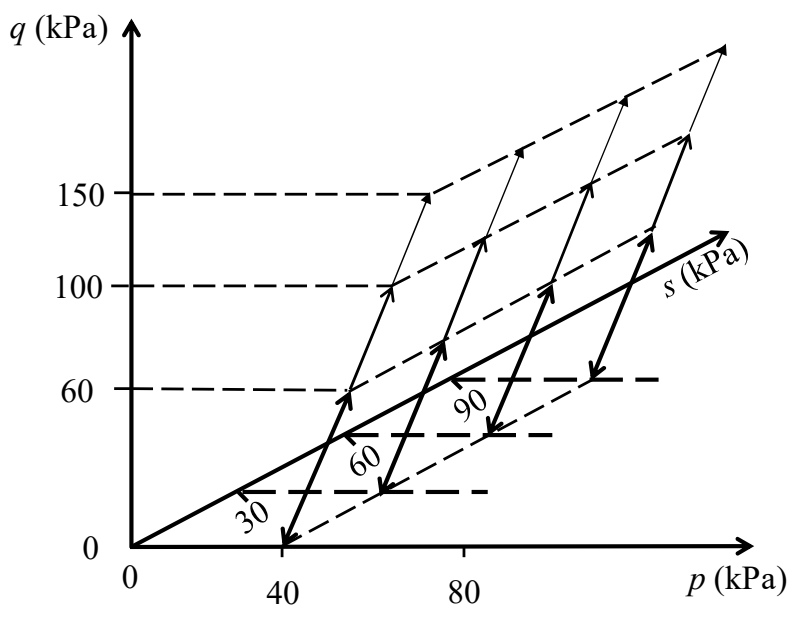

(b) Stress paths in a $(p, q, s)$ space. 


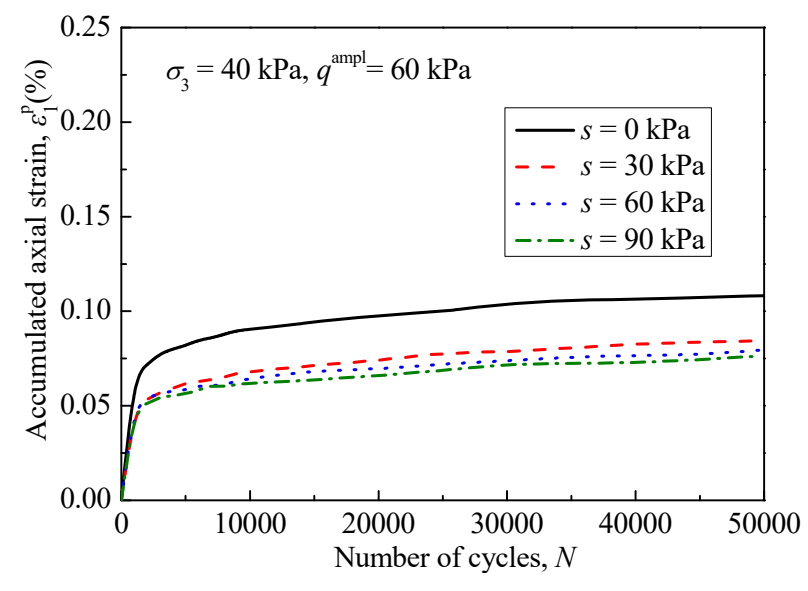

530

531

(a) $q^{\mathrm{ampl}}=60 \mathrm{kPa}$

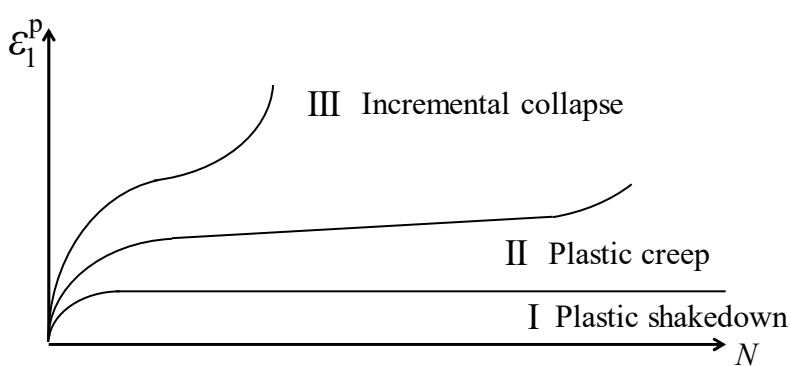

(a)

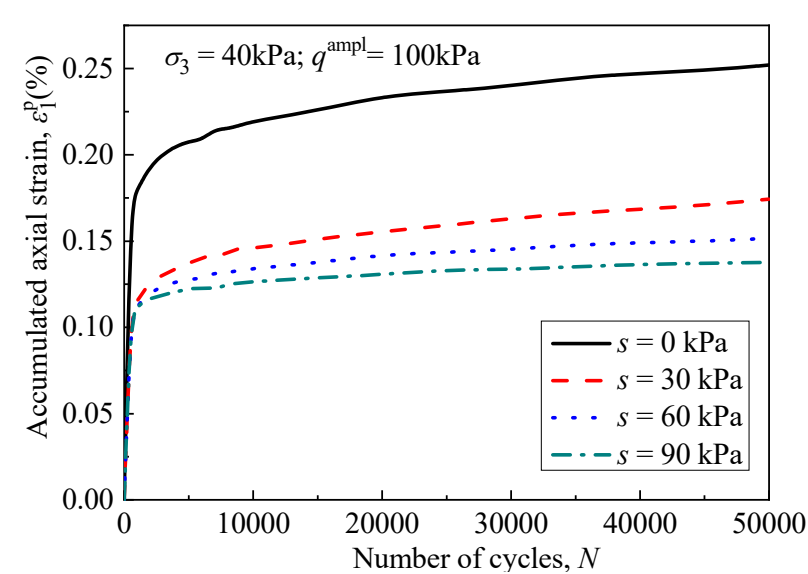

(b) $q^{\mathrm{ampl}}=100 \mathrm{kPa}$

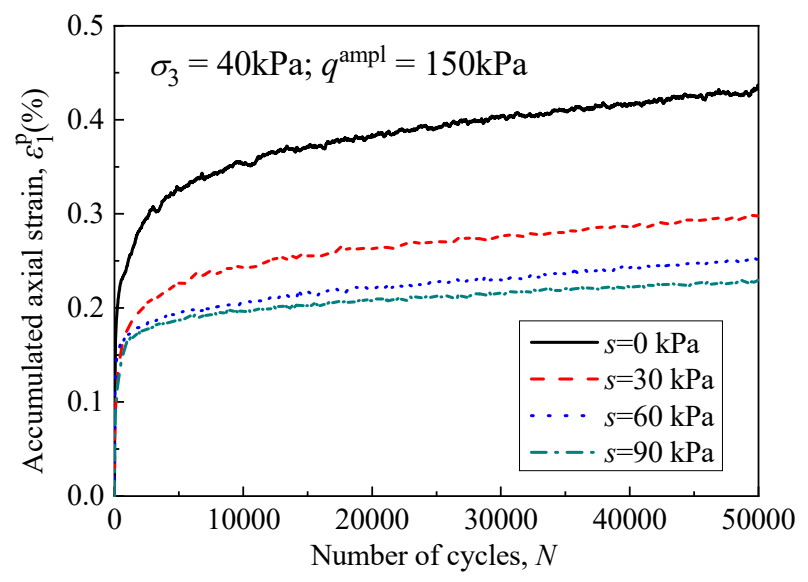

(c) $q^{\mathrm{ampl}}=150 \mathrm{kPa}$

FIGURE 3 Cyclic triaxial tests on unsaturated crushed tuff aggregates. Accumulated axial strain versus $N$ under different suction

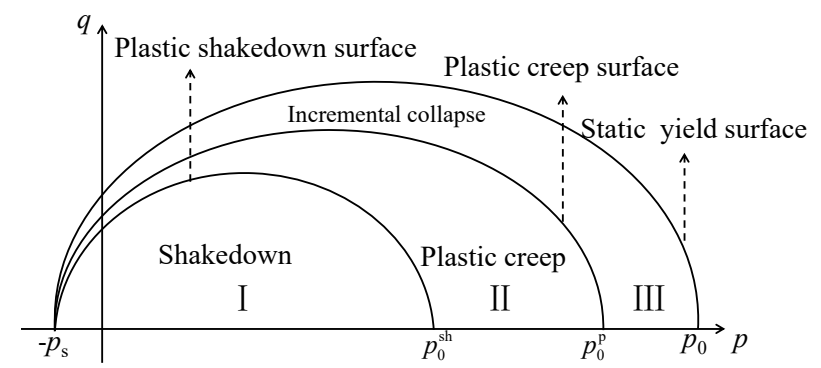

(b)

FIGURE 4 Three categories of cyclic behaviors within shakedown theory. a) Accumulation of plastic strain in terms of $N$. b) Deformation regions in triaxial stress space for a given suction 


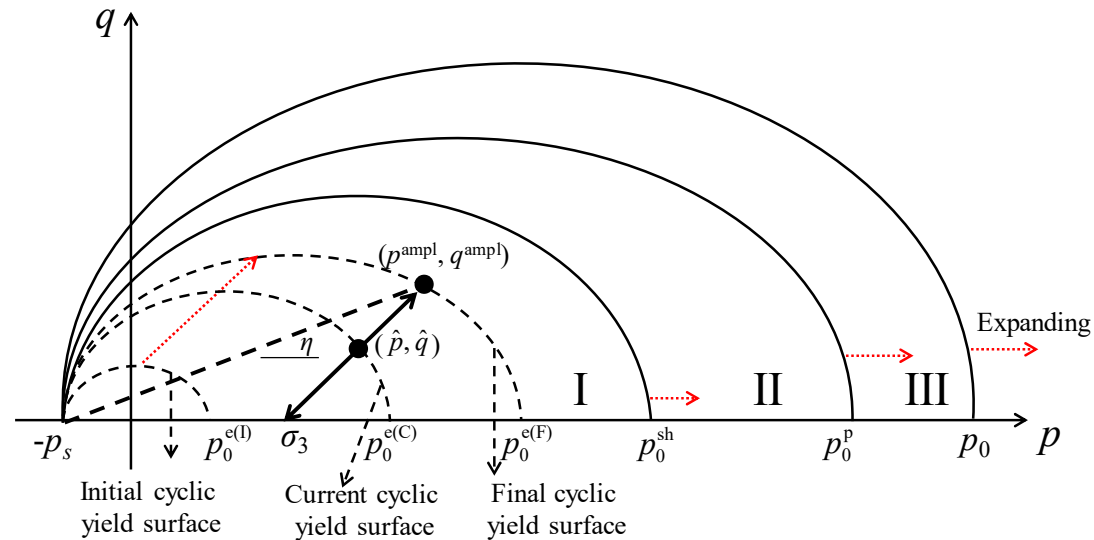

(a) Cyclic stress in section I (shakedown)

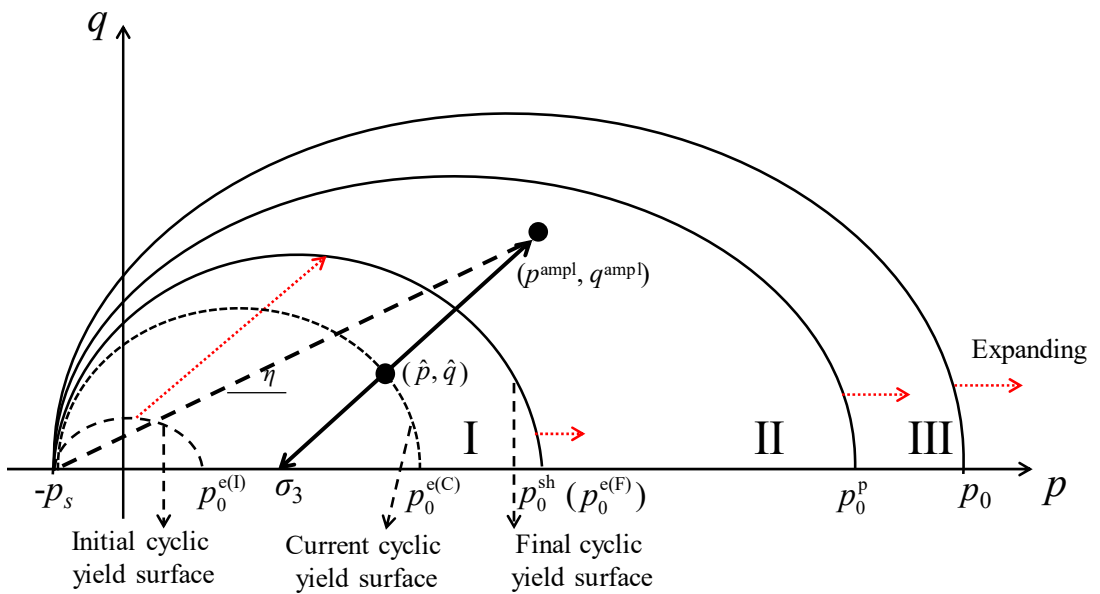

(b) cyclic stress in section II (plastic creep)

FIGURE 5 Extended BBM for cyclic loading

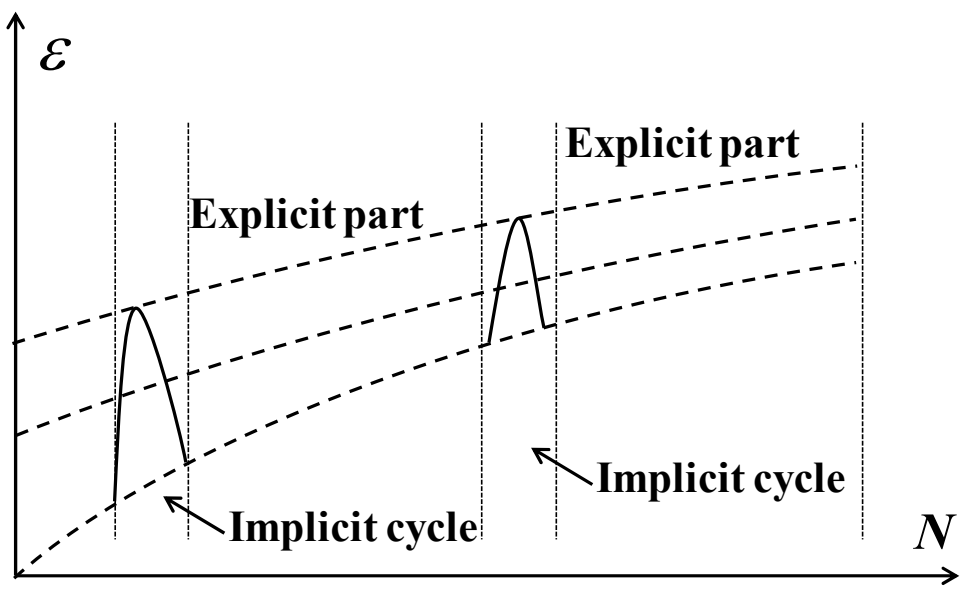

FIGURE 6 Schematic diagram of explicit method 


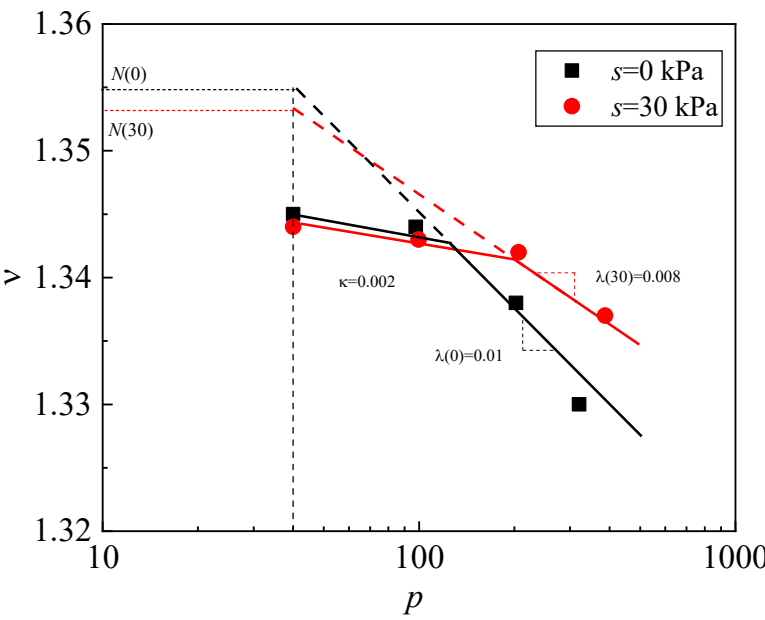

(a) compression test

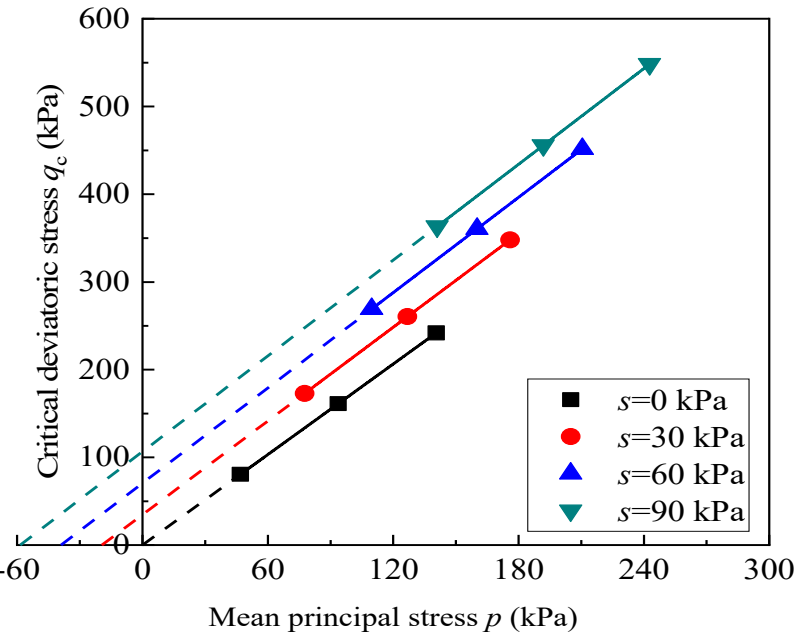

(b) tri-axial shear test

FIGURE 7 Test results for BBM parameter calibration

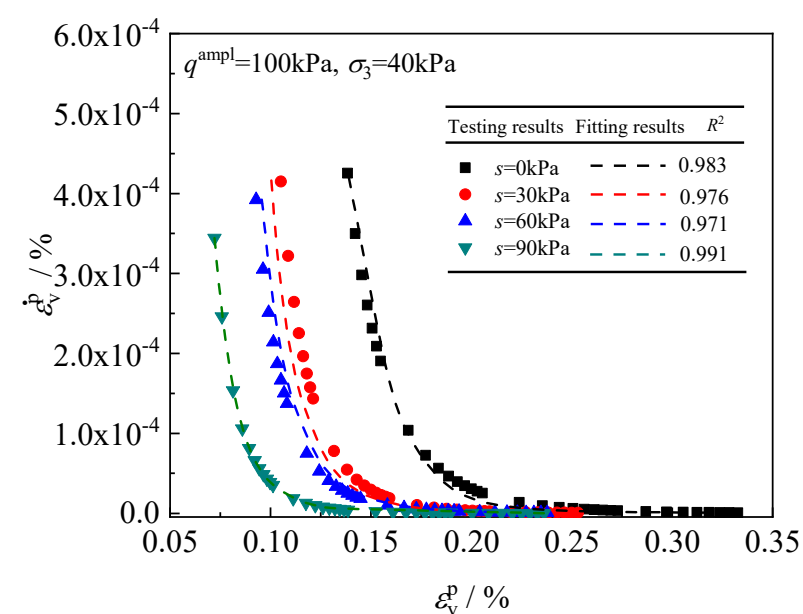

(a) volumetric strain rate

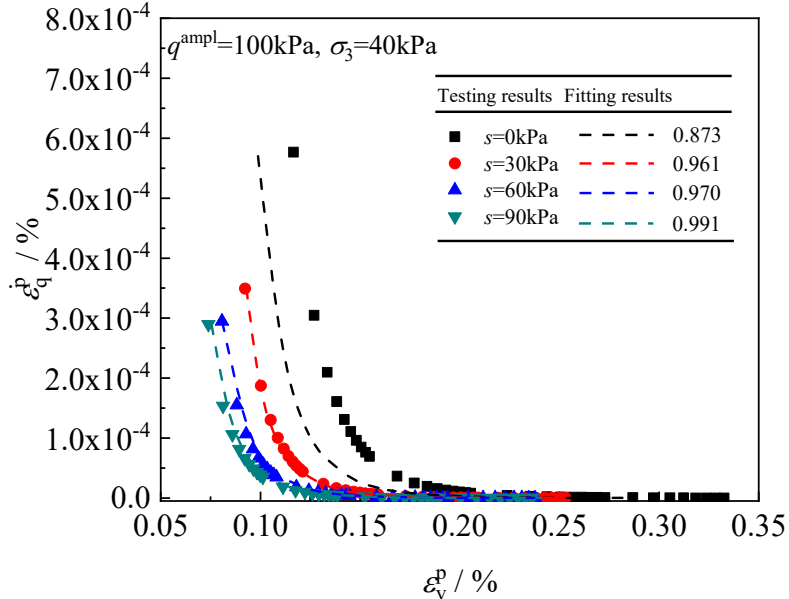

(b) deviatoric strain rate

FIGURE 8 Accumulated strain rate versus accumulated volumetric strain, $q^{\text {ampl }}=100 \mathrm{kPa}$. 


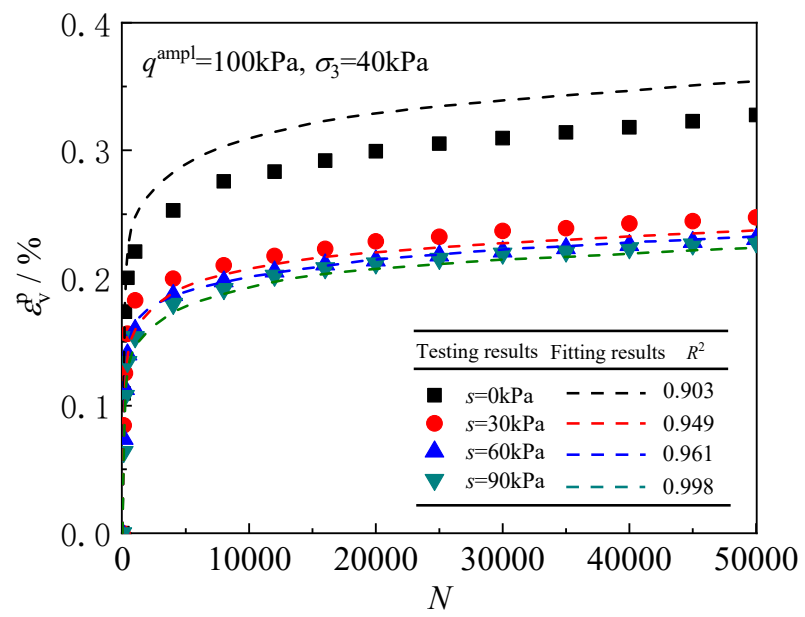

(a) volumetric strain

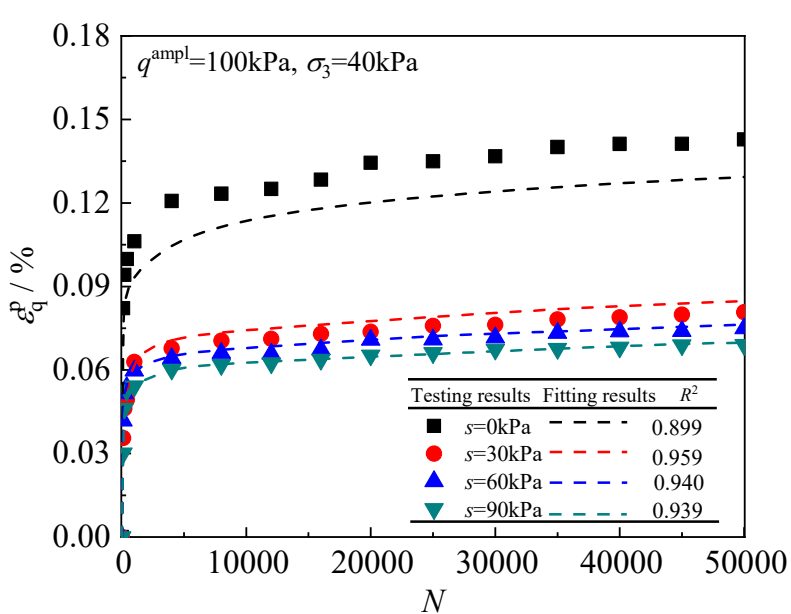

(b) deviatoric strain

FIGURE 9 Comparison between predicted and tested accumulated strain for $q=100 \mathrm{kPa}$.

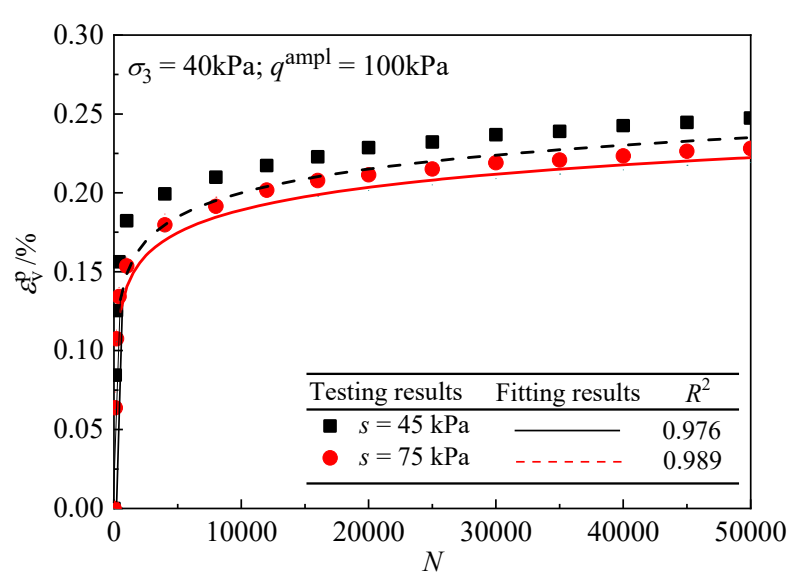

(a) Accumulated volumetric strain

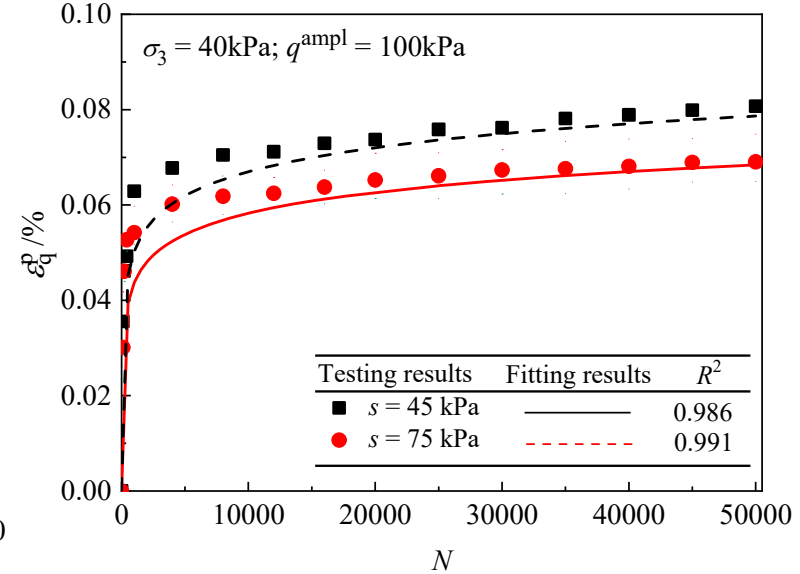

(b) Accumulated deviatoric strain

FIGURE 10 Model validation for $s=45 \mathrm{kPa}$ and $75 \mathrm{kPa}$ 
561

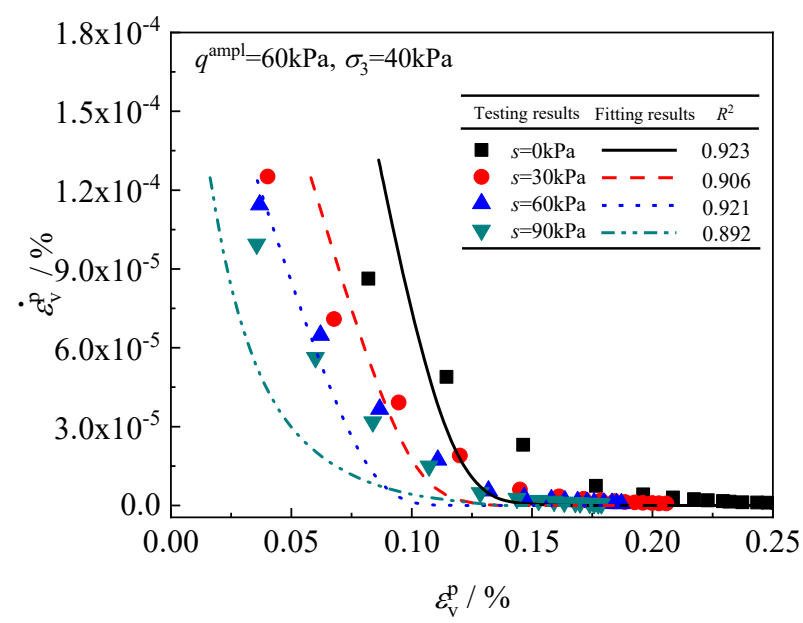

(a) volumetric strain rate

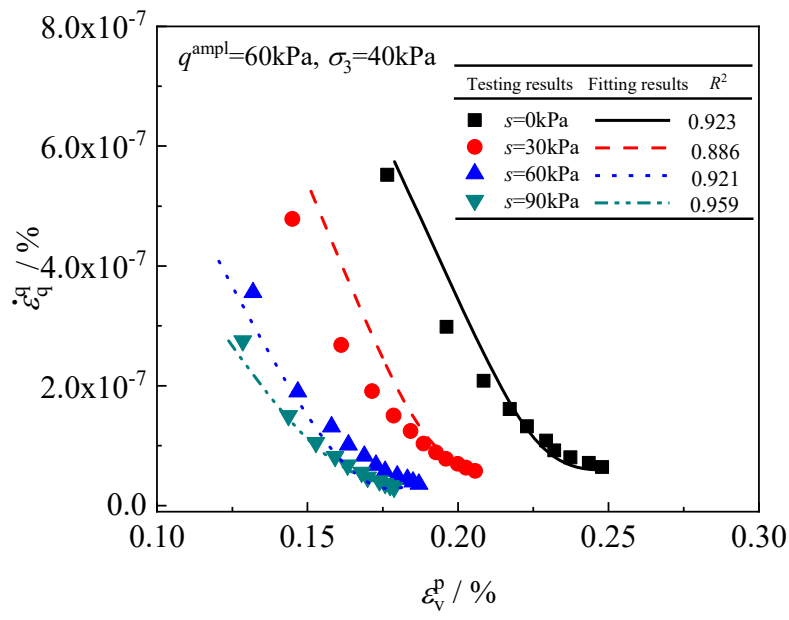

(b) deviatoric strain rate

FIGURE 11 Accumulated strain rate versus accumulated volumetric strain, $q^{\text {ampl }}=60 \mathrm{kPa}$.

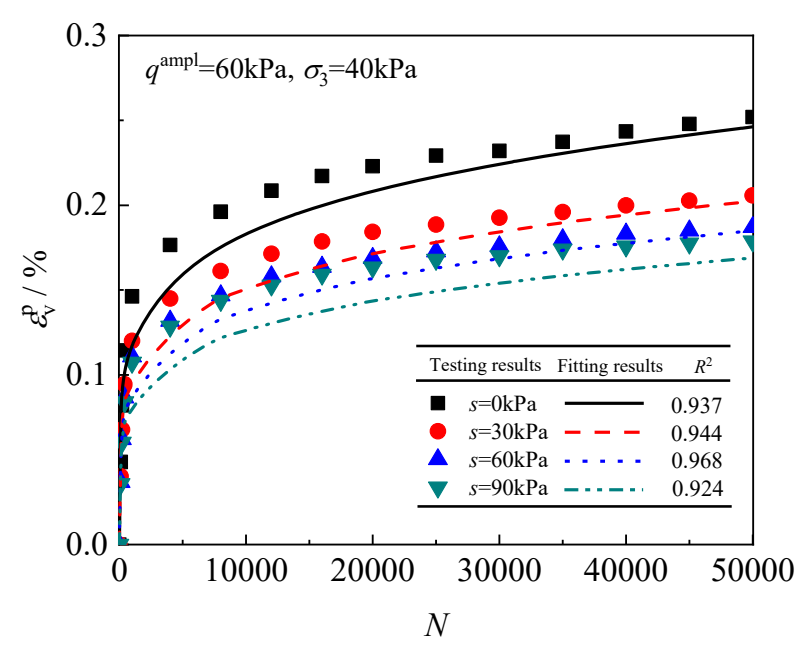

(a) volumetric strain

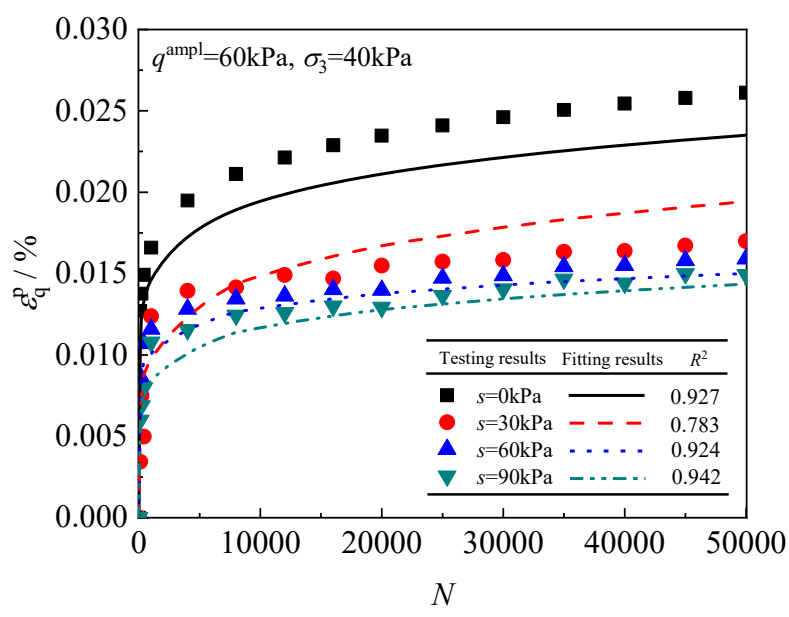

(b) deviatoric strain

FIGURE 12 Accumulated volumetric and deviatoric strains with the number of cycles, $q=60 \mathrm{kPa}$ 


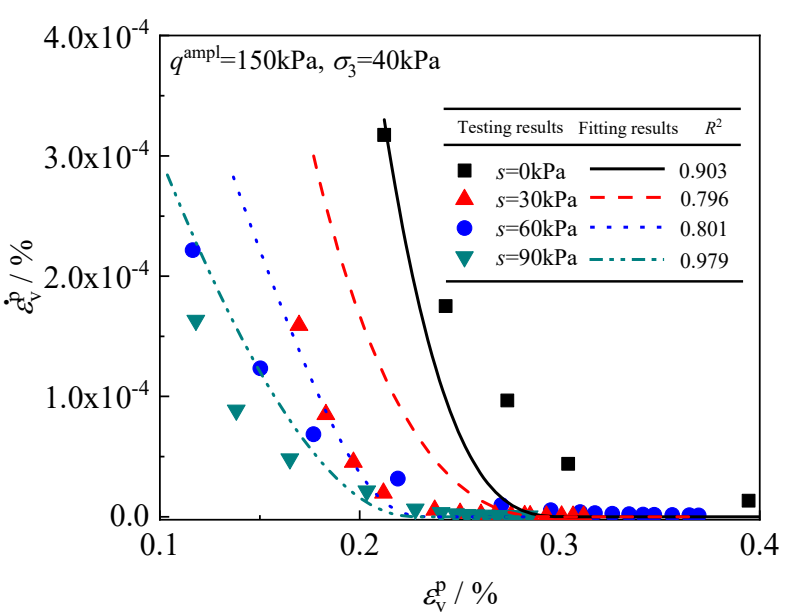

(a) volumetric strain rate

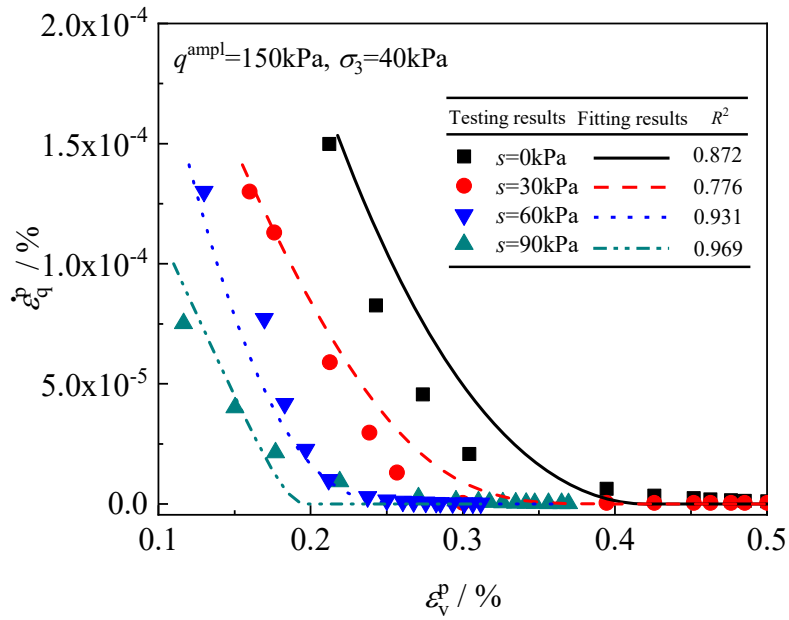

(b) deviatoric strain rate.

FIGURE 13 Accumulated strain rate versus accumulated volumetric strain, $q^{\mathrm{ampl}}=150 \mathrm{kPa}$.

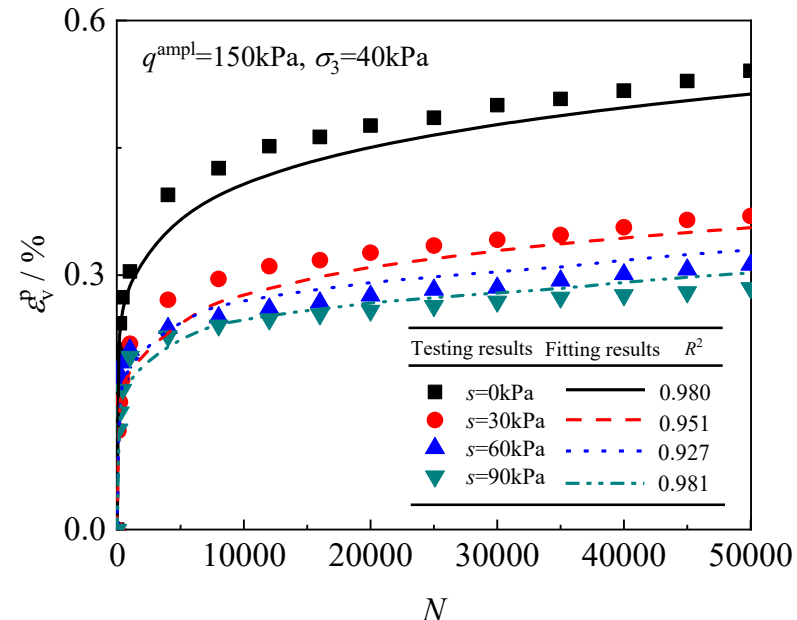

(a) volumetric strain

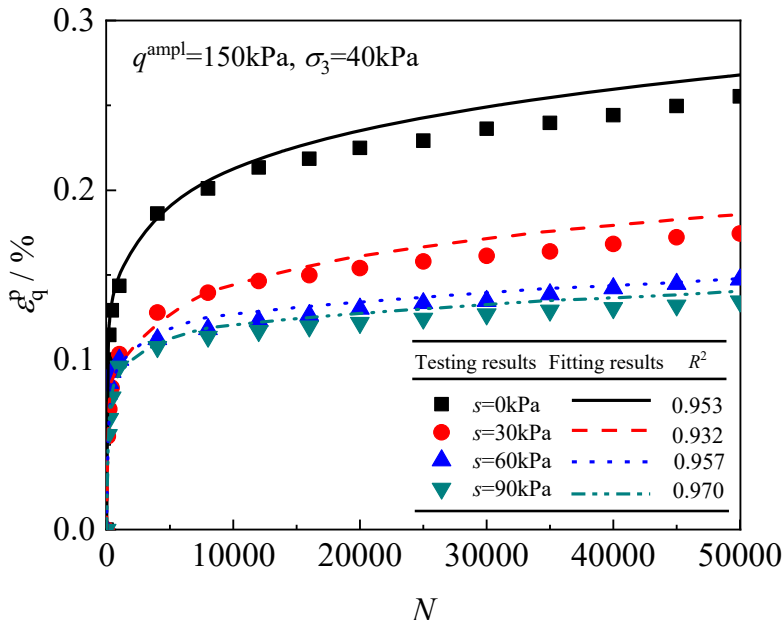

(b) deviatoric strain

573 FIGURE 14 Accumulated volumetric and deviatoric strains with the number of cycles, $q=150 \mathrm{kPa}$ 